\title{
Review
}

\section{Switchable Cobalt Coordination Polymers: Spin Crossover and Valence Tautomerism}

Olga Drath, Colette Boskovic*

School of Chemistry, University of Melbourne, Victoria, 3010, Australia

\section{Contents}

1. Introduction

2. Spin crossover in cobalt compounds

3. Valence tautomerism in cobalt compounds

4. One dimensional switchable cobalt coordination polymers

4.1 Spin crossover in one dimensional cobalt coordination polymers

4.2 Valence tautomerism in one dimensional cobalt coordination polymers

5 Two dimensional switchable cobalt coordination polymers

6. New directions with switchable cobalt coordination polymers

7. Concluding remarks

References 


\title{
RESEARCH HIGHLIGHTS
}

- Switchable cobalt coordination polymers exhibit valence tautomeric or spin crossover transitions upon application of an external stimulus such as heating or cooling.

- One- and two-dimensional switchable cobalt coordination polymers are reviewed.

- New directions in the field oriented towards materials applications include incorporating switchable cobalt coordination polymers into nano- and microparticles and grafting the particles onto surfaces.

\section{KEYWORDS}

spin crossover; valence tautomerism; redox isomerism; coordination polymers; cobalt; metal organic frameworks

\begin{abstract}
Electronically labile, or switchable, cobalt coordination polymers exhibit reversible spin crossover (SCO) or valence tautomeric (VT) transitions upon the application of an external stimulus, such as temperature variation. Spin crossover transitions at pseudo-octahedral cobalt(II) centers with an appropriate ligand field involve a heating-induced transition from the low-spin to high-spin electronic configurations. Valence tautomeric transitions are most commonly observed for cobalt-dioxolene systems, which undergo an intramolecular electron transfer and concomitant spin transition at the cobalt center, from low-spin-cobalt(III)catecholate at low temperature to high-spin-cobalt(II)-semiquinonate upon heating. The VT transition can also be induced by light, while the cobalt(II) SCO transition cannot. Incorporation of these switchable moieties into coordination polymers (CPs) is generally achieved using polytopic nitrogen-donor linking ligands. All but one of the switchable cobalt CPs that have been structurally characterized are 1D chains, most of which exhibit VT
\end{abstract}


transitions rather than SCO. There is a single example of a switchable $2 \mathrm{D}$ cobalt $\mathrm{CP}$ where VT cobalt-dioxolene moieties are linked by a tetratopic nitrogen-donor bridging ligand. Efforts to confer the VT properties to compounds suitable for applications as materials or in devices have mainly focused on the incorporation of the 1D chain VT CPs into nano- and microparticles, in which the VT transition is generally maintained. Valence tautomeric nanoparticles synthesized from 1D chain CPs have been grafted on to gold surfaces as self-assembled monolayers. 


\section{Introduction}

Prussian blue is an early example of a functional coordination polymer $(\mathrm{CP})$, with its use as a pigment dating back to the early $18^{\text {th }}$ century. The structure of Prussian blue involves cyanide ligands that link iron centers into an infinite 3D network [1]. Replacement of the cyanide ligands with larger ditopic organic ligands that can link metal centers into potentially porous frameworks has afforded a substantial field of contemporary chemical endeavor. Many thousands of CPs, or metal-organic-frameworks (MOFs), have now been synthesized and structurally characterized [2-6]. Research in the field has recently shifted from the original emphasis on generating new structural types to dedicated efforts to optimize the chemical and physical features to develop materials for future applications ranging from sensing, separations, gas storage and heterogeneous catalysis [7-10]. Prussian blue is comprised of both $\mathrm{Fe}(\mathrm{II})$ and $\mathrm{Fe}(\mathrm{III})$ centers and the intense blue color that gives rise to its use as a pigment is due to an intervalence charge transfer between the mixed-valence iron centers [11]. Thus Prussian blue is also the first example of a synthetic $\mathrm{CP}$ with functionality derived from its electronic properties, acting as a forerunner for the interest in CPs with electronic features that can potentially be harnessed in devices and new materials. Electronic properties that have been identified in CPs as relevant for future applications include luminescence, conduction and nonlinear optical and magnetic properties, while CPs may also one day find employment in optoelectonic or photonic devices [10,12-14].

A class of CPs that are of interest for their electronic properties are those that undergo spin crossover (SCO). This phenomenon involves a stimulated reversible spin transition, generally at an octahedral metal center with $\mathrm{d}^{4}$ to $\mathrm{d}^{7}$ electronic configuration. The best known class of SCO compounds feature the $\mathrm{d}^{6} \mathrm{Fe}(\mathrm{II})$ ion, for which the transition is most commonly induced by heating/cooling. However, other stimuli are also active, notably irradiation with visible light, making use of so-called light-induced excited spin-state trapping (LIESST), 
which can be reversed through irradiation at a different wavelength via the reverse-LIESST effect [15-17]. Ranging from 1D chains to 2D nets and 3D networks, there are a number examples of CPs that exhibit SCO at Fe(II) centers [18-20]. Of great importance to the field of SCO is pioneering work from O Kahn et al. who identified SCO in the $1 \mathrm{D}$ polymers [Fe(4R-1,2,4-triazole $\left.)_{3}\right]^{2+}\left(\mathrm{R}=\mathrm{H}, \mathrm{NH}_{2}\right.$ and $\left.\mathrm{CH}_{2} \mathrm{CH}_{2} \mathrm{OH}\right)$, which are bistable with substantial hysteresis at room temperature [21]. Another interesting family of SCO CPs are the heterometallic 3D Hofmann networks of general formula $\left\{\mathrm{Fe}(\mathrm{NLN})\left[\mathrm{M}(\mathrm{CN})_{4}\right]\right\}(\mathrm{NLN}=$ ditopic $\mathrm{N}$-donor ligand such as pyrazine (pyz) and $\mathrm{M}=\mathrm{Ni}, \mathrm{Pd}$ or $\mathrm{Pt}$ ), which can exhibit guest-sensitive hysteresis and multi-step SCO transitions that may ultimately find application in gas sensors or stimuli-responsive switching devices [22-29] .

After $\mathrm{Fe}(\mathrm{II})$, the $\mathrm{d}^{7} \mathrm{Co}(\mathrm{II})$ ion is the next most prevalent ion for $\mathrm{SCO}[30,31]$, although the field of SCO of Co(II) systems is far less developed and SCO has been reported for relatively few $\mathrm{Co}$ (II) CPs. Instead there are more examples of Co CPs that exhibit the related, but more complicated, phenomenon of valence tautomerism [32-40]. Also predominantly stimulated by temperature variation, valence tautomeric (VT) transitions involve an intramolecular electron transfer between a redox-active metal center and a coordinated ligand that is also redox-active. By far the largest family of VT compounds are cobalt-dioxolene systems, for which SCO accompanies the electron transfer. All cobalt CPs that exhibit VT are based on linked cobalt-dioxolene units. Compounds that exhibit either VT or SCO can be described as electronically labile and they exhibit a number of features in common. For future practical applications it is important that the transitions are reversible and thus the systems are "switchable". If hysteresis accompanies the transition, the system is said to be bistable, which is essentially for applications in display devices or data storage. It is also important that the two forms that are interconverted can be readily distinguished. This is generally true for both SCO and VT compounds based on cobalt, for which the species with the two different 
electronic states and/or charge distributions, typically have distinctly different structural, optical and magnetic properties. Thus the transitions can be monitored by a variety of physical techniques, including magnetic susceptibility, X-ray diffraction and EPR or electronic spectroscopy. Both SCO and VT transitions can occur in solid and solution states, although the transition characteristics often differ in different media.

There are several motivations for extending switchable SCO or VT systems from discrete metal complexes into 1D, 2D or 3D CPs. First, arranging the switching units into infinite CPs can substantially increase the cooperativity of the transition as it propagates through the $\mathrm{CP}$ with a domino-like effect, affording the abrupt transitions and possibly bistability that are important for applications. Second, porous 2D and 3D materials can exhibit host-guest interactions that can tune the characteristics of the electronic transition and give rise to applications related to sensing, separation or heterogeneous catalysis. Third, the combination of SCO or VT units into CPs with other functional units can potentially give rise to multifunctionality. Finally, CPs can in some instances be readily incorporated into materials such as gels, films, fibres, nanoparticles and microspheres [41-43], which may facilitate the exploitation of the VT/SCO properties in devices. The most explored electronically labile, or switchable, CPs are those that feature $\mathrm{SCO}$ at $\mathrm{Fe}(\mathrm{II})$ and the reader is referred to several reviews of this topic [18-20]. In contrast, the area of cobalt CPs that exhibit SCO and/or VT transitions is yet to be reviewed in a dedicated way and it is the intention of the present work to fill this void.

\section{Spin Crossover in Cobalt Compounds}

Thermally induced spin crossover in Co(II) compounds generally involves the transfer of an electron from a $\mathrm{t}_{2 \mathrm{~g}}$ orbital of a low-spin (LS) pseudo-octahedral Co(II) ion with a ${ }^{2} \mathrm{E}\left(\mathrm{t}_{2 \mathrm{~g}}{ }^{6} \mathrm{eg}_{\mathrm{g}}{ }^{1}\right)$ ground term to an antibonding e ${ }_{\mathrm{g}}{ }^{*}$ orbital, affording the ${ }^{4} \mathrm{~T}_{1}\left(\mathrm{t}_{2 \mathrm{~g}}{ }^{5} \mathrm{e}_{\mathrm{g}}{ }^{2}\right)$ high-spin (HS) state (Fig. 
1). A spin change of $\Delta S=1$ is associated with this transition from $S=1 / 2$ to $S=3 / 2$, which is less that the $\Delta S$ value of 2 for $\mathrm{SCO}$ at $\mathrm{Fe}$ (II) (from $S=0$ to $S=2$ ). The ${ }^{4} \mathrm{~T}_{1} \mathrm{HS}$ octahedral $\mathrm{Co}(\mathrm{II})$ ion has significant first order orbital angular momentum, while the LS Co(II) ion tends to undergo Jahn-Teller distortion.

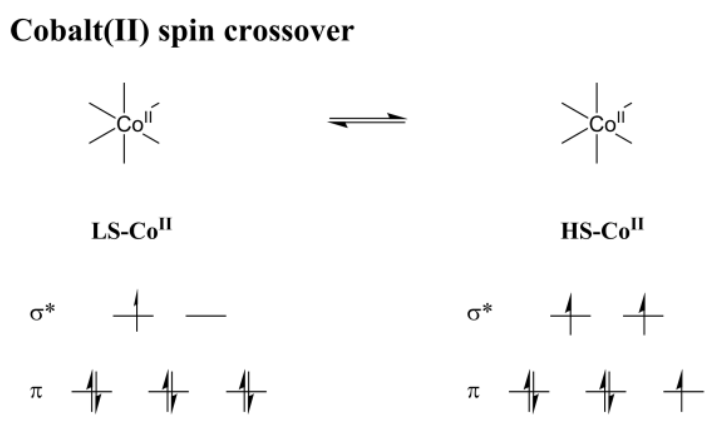

Cobalt-dioxolene valence tautomerism

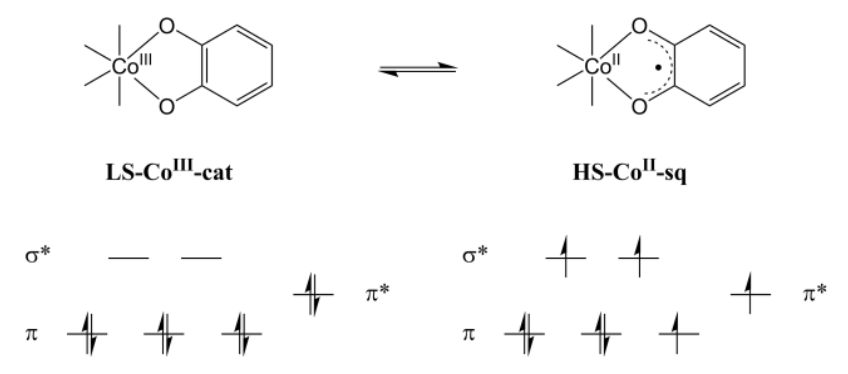

Fig. 1. Electronic structures for cobalt(II) SCO and cobalt-dioxolene VT transitions.

Spin crossover occurs most commonly for $\mathrm{Co}(\mathrm{II})$ complexes with an $\mathrm{N}_{6}$ coordination sphere, which can be realized using combinations of monodentate and chelating N-donor ligands. The most common examples are $\left[\mathrm{Co}\left(\mathrm{N}_{3} \mathrm{~L}\right)_{2}\right]^{2+}$ complexes, where $\mathrm{N}_{3} \mathrm{~L}$ is a tridentate triimine ligand such as terpyridine. There are also examples of $\left[\mathrm{Co}\left(\mathrm{N}_{2} \mathrm{~L}\right)_{3}\right]^{2+} \mathrm{SCO}$ complexes, where $\mathrm{N}_{2} \mathrm{~L}$ is a bidentate diimine ligand. For isostructural complexes, the crystal field splitting is larger for $\mathrm{Fe}(\mathrm{II})$ than for $\mathrm{Co}(\mathrm{II})$, consequently ligand sets that are appropriate to induce SCO in an $\mathrm{Fe}(\mathrm{II})$ complex may not give rise to $\mathrm{SCO}$ in $\mathrm{Co}$ (II). The other property distinguishing 
$\mathrm{Co}$ (II) SCO is the strong Jahn-Teller effect in the LS state, which arises from the singly occupied $\mathrm{e}_{\mathrm{g}}{ }^{*}$ orbital. Quite often, the coordination geometry of a LS-Co(II) ion is markedly distorted from octahedral. The $\left[\mathrm{Co}\left(\mathrm{N}_{3} \mathrm{~L}\right)_{2}\right]^{2+}$ complexes in the LS state consist of two transdisposed shorter axial bonds (ca. $1.9 \AA$ Co-N distances) and four longer equatorial bonds (ca. 2.1 $\AA$ Co-N distances). Associated with the increased population of the antibonding $\mathrm{e}_{\mathrm{g}}$ * orbitals, the SCO transition induces an increase in bond lengths, which is observed mainly for the two axial bonds while the equatorial bonds elongate to a very small extent, resulting in a much less distorted octahedral geometry in the HS state. The average difference in the six bond lengths between the LS and HS Co(II) states is around 0.07-0.11 $\AA$ versus $0.18-0.20 \AA$ for SCO in Fe(II) complexes [31]. Thermally-induced SCO transitions in Co(II) complexes are entropically driven, with the entropy gain arising from both the higher density of vibrational states of the HS-Co(II) complex (due to the longer Co-N bond lengths) and the higher spin state degeneracy of HS-Co(II) versus LS-Co(II). A consequence of the smaller difference in bond lengths for $\mathrm{Co}$ (II) SCO systems, and the resulting weaker intermolecular cooperativity, is that the transitions are generally more gradual than for Fe(II) and are often incomplete, with fewer examples of hysteresis. The critical temperature $\left(T_{1 / 2}\right)$ of a thermally-induced SCO transition is defined as the temperature at which equal quantities of the two spin states co-exist, with $T_{1 / 2}$ values in the range 50-350 $\mathrm{K}$ reported for the $\mathrm{Co}(\mathrm{II}) \mathrm{SCO}$ compounds that exhibit complete transitions and hysteresis in the solid state $[18,44]$. Like both SCO Fe(II) complexes and VT Co complexes (see later), the SCO transition can also be induced or facilitated by application of pressure [45]. However, unlike the other two cases, a light-induced SCO transition is yet to be reported for a $\operatorname{Co}(\mathrm{II})$ complex, which can be attributed to the relatively small bond length differences between the LS and HS Co(II) states and the consequent rapid relaxation of a possible light-induced HS state to rapid tunneling [46]. 
In addition to the typical $\mathrm{N}_{6}$ coordination sphere around the Co center, SCO has also been observed for a number of $\mathrm{Co}(\mathrm{II})$ complexes with an $\mathrm{N}_{4} \mathrm{O}_{2}$ coordination sphere with the $\mathrm{O}$ atoms either cis- or trans-disposed. An interesting example of this is the complex $\left[\mathrm{Co}{ }^{\mathrm{II}}(\mathrm{L}-\right.$ $\left.\left.\mathrm{N}_{4} t \mathrm{Bu}_{2}\right)(3,5-\mathrm{dbsq})\right]^{+} \quad\left(\mathrm{L}-\mathrm{N}_{4} t \mathrm{Bu}_{2}=\mathrm{N}, \mathrm{N}^{\prime}\right.$-di-tert-butyl-2,11-diaza[3.3](2,6)pyridinophane; $3,5 \mathrm{dbsq}^{-}=3,5$-di-tert-butylsemiquinone) $[47,48]$, which is the first reported cobalt-dioxolene complex to exhibit a SCO rather than a VT transition. Various physical techniques demonstrate unequivocally that this complex maintains the $\mathrm{Co}(\mathrm{II})$-semiquinonate $\left(\mathrm{sq}^{-}\right)$charge distribution at all temperatures, but undergoes a LS to $\mathrm{HS}$ SCO at the Co(II) center in both solid state and solution. The LS-Co(II)-sq coupling is ferromagnetic, while the significant first order orbital angular momentum of the HS-Co(II) state makes unambiguous determination of the sign of the coupling difficult. Intriguingly, the analogous complex with the methylated macrocyclic

ligand, $\quad\left[\mathrm{Co}^{\mathrm{III}}\left(\mathrm{L}-\mathrm{N}_{4} t \mathrm{Me}_{2}\right)(3,5-\mathrm{dbcat})\right]^{+} \quad\left(\mathrm{L}-\mathrm{N}_{4} t \mathrm{Me}_{2} \quad=\quad\right.$ N,N'-di-tert-methyl-2,11diaza[3.3](2,6)pyridinophane; 3,5-dbcat ${ }^{2-}=3,5$-di-tert-butylcatechol), instead exhibits a different distribution of the same overall charge, existing in the temperature-invariant diamagnetic LS-Co(III)-catechol ( cat $\left.^{2-}\right)$ state. It appears that steric hindrance associated with the tert-butyl substituents of the pyridinophane macrocycle enforces long axial bond lengths, which prevents sufficient electron density being supplied to the cobalt ion to allow its oxidation to $\mathrm{Co}(\mathrm{III})$ by the coordinated semiquinonate ligand, as is observed for the analogue with methyl substituents on the macrocycle. This case emphasizes the importance of the interplay of subtle steric and electronic effects in controlling the redox states, charge distribution and transitions in complexes where both intramolecular redox reactions and spin state transitions are possible.

\section{Valence Tautomerism in Cobalt Compounds}

The majority of cobalt-dioxolene compounds that undergo a transition upon temperature variation undergo a VT transition, from LS-Co(III)-cat to HS-Co(II)-sq upon heating, which 
involves coupled electron transfer and spin transition at the cobalt center (Fig. 1). The low temperature tautomer contains the ${ }^{1} \mathrm{Ag}_{\mathrm{g}}\left(\mathrm{t}_{2 \mathrm{~g}}{ }^{6}\right) \mathrm{Co}(\mathrm{III})$ ion and is diamagnetic $(S=0)$, while the nature of the exchange coupling between the HS-Co(II) ion and the semiquinonate ligand is unclear. Valence tautomeric cobalt-dioxolene complexes typically possess a $\mathrm{N}_{2} \mathrm{O}_{4}$ or $\mathrm{N}_{4} \mathrm{O}_{2}$ coordination sphere and belong to one of the families: $\left[\left(\mathrm{Co}(\mathrm{NL})_{2}(\mathrm{sq})(\operatorname{diox})\right]\right.$, $\left[\mathrm{Co}\left(\mathrm{N}_{2} \mathrm{~L}\right)(\mathrm{sq})(\operatorname{diox})\right]$, or $\left[\mathrm{Co}\left(\mathrm{N}_{4} \mathrm{~L}\right)(\operatorname{diox})\right]^{+}\left(\mathrm{NL}=\right.$ monodentate $\mathrm{N}$-donor ligand, $\mathrm{NL}_{2}=$ bidentate diimine ligand, $\mathrm{NL}_{4}=$ tetradentate $\mathrm{N}$-donor ligand; the dioxolene (diox) ligand is in the catecholate form at low temperature and the semiquinonate form at high temperature). The most commonly used dioxolene ligand is 3,5-di-tert-butyldioxolene (3,5-dbdiox), which tunes the $\mathrm{Co}(\mathrm{III} / \mathrm{II})$ redox potential to be suitable for thermally-induced VT transitions in the practically accessible 50-400 K temperature range. The VT transition also induces molecular expansion upon heating and the average difference in the six Co-N/O bond lengths between the LS-Co(III)-cat and HS-Co(II)-sq tautomers is around 0.16-0.22 $\AA$, significantly more than for SCO in Co(II). The $T_{1 / 2}$ values for cobalt-dioxolene VT transitions in the solid state are in the range 100-390 K. Like SCO transitions, thermally-induced VT transitions in cobaltdioxolene complexes are also entropically driven. However, unlike SCO in $\mathrm{Co}(\mathrm{II})$ compounds, the VT transition in cobalt-dioxolene complexes can be induced by irradiation with visible light, analogous to the LIESST process [36]. The reverse process can also be induced by irradiation with light of different wavelengths. Other methods of stimulating VT transitions in Cobalt-dioxolene systems include pressure, magnetic or electric field, irradiation with both soft and hard X-rays [49-53].

\section{One dimensional switchable cobalt coordination polymers}

To date, less than 20 different structural families of cobalt CPs have been found to exhibit either SCO or VT transitions (Table 1), with many more examples of VT transitions rather than 
SCO. All but one of the reported compounds are $1 \mathrm{D}$ chains, there is a single example of a $2 \mathrm{D}$ VT CP, while a 3D cobalt CP that exhibits either an SCO or VT transition has proved elusive thus far. Synthetic approaches have focused on careful choice of polytopic linking ligands (Fig. 2) to link SCO or VT Co-containing units. For both SCO and VT systems, N-donor linking ligands have been used for all compounds that have been structurally characterized. 
Table 1. Crystallographically characterized cobalt SCO and VT coordination polymers

\begin{tabular}{|c|c|c|c|c|c|c|c|}
\hline $\begin{array}{l}1 \mathrm{D} \\
\text { or } \\
2 \mathrm{D}\end{array}$ & $\begin{array}{l}\text { SCO } \\
\text { or } \\
\text { VT }\end{array}$ & Formula $^{1}$ & $\begin{array}{l}\text { Linking } \\
\text { ligand }\end{array}$ & $\begin{array}{l}\text { Stereochemistry } \\
\text { of linking } \\
\text { ligands }\end{array}$ & Thermal transition & $\begin{array}{l}\text { Effective } \\
T_{\text {LIESST }}\end{array}$ & Ref. \\
\hline 1D & $\mathrm{SCO}$ & {$\left[\mathrm{CoCl}_{2}(\right.$ pyterpy $\left.)\right] \cdot 2 \mathrm{H}_{2} \mathrm{O}$} & pyterpy & - & abrupt, $T_{1 / 2}=223 \mathrm{~K}$, hysteresis $\Delta T=1 \mathrm{~K}$ & - & 54,55 \\
\hline 1D & $\mathrm{SCO}$ & {$\left[\mathrm{CoBr}_{2}\right.$ (pyterpy)] } & pyterpy & - & gradual & - & 55 \\
\hline $1 \mathrm{D}$ & $\mathrm{SCO}$ & {$[\mathrm{Co}(\mathrm{dca})($ enbzpy $)] \mathrm{ClO}_{4}$} & dca & trans & $\begin{array}{l}\text { abrupt, } T_{1 / 2}=192 \mathrm{~K} \text {, incomplete at low } \mathrm{T} \\
\text { hysteresis: } \Delta T=3 \mathrm{~K}\end{array}$ & - & 56,57 \\
\hline 1D & SCO & {$[\mathrm{Co}(\mathrm{dca})($ enbzpy $)] \mathrm{PF}_{6}$} & dca & trans & gradual & - & 57 \\
\hline 1D & VT & {$\left[\mathrm{Co}(3,5-\mathrm{dbdiox})_{2}(\mathrm{dpg})\right] \cdot 2\left(3,5-\mathrm{dbcatH}_{2}\right)$} & dpg & cis & gradual, pressure-dependent. & $83 \mathrm{~K}$ & 60 \\
\hline 1D & VT & {$\left[\mathrm{Co}(3,5-\mathrm{dbdiox})_{2}(\right.$ bpee $\left.)\right] \cdot 2 \mathrm{MeCN} \cdot 2 \mathrm{H}_{2} \mathrm{O}$} & bpee & trans & abrupt, $T_{1 / 2}=348 \mathrm{~K}$ & $52 \mathrm{~K}$ & 61 \\
\hline 1D & VT & $\left[\mathrm{Co}(3,5 \text {-dbdiox })_{2}\right.$ (bpee $\left.)\right]$ & bpee & trans & gradual & - & 61 \\
\hline 1D & VT & {$\left[\mathrm{Co}(3,5-\mathrm{dbdiox})_{2}\right.$ (azpy)] $2 \mathrm{MeCN} \cdot 2 \mathrm{H}_{2} \mathrm{O}$} & azpy & trans & abrupt, $T_{1 / 2}=348 \mathrm{~K}$ & - & 61 \\
\hline $1 \mathrm{D}$ & VT & {$\left[\mathrm{Co}(3,5 \text {-dbdiox })_{2}(\right.$ azpy $\left.)\right] \cdot 2 \mathrm{EtOH}$} & azpy & trans & gradual & $55 \mathrm{~K}$ & 62 \\
\hline 1D & VT & {$\left[\mathrm{Co}(3,5 \text {-dbdiox })_{2}\right.$ (azpy) $]$} & azpy & trans & gradual & - & 61 \\
\hline 1D & VT & {$\left[\mathrm{Co}(3,5 \text {-dbdiox })_{2}(\mathrm{bpb})\right] \cdot 2 \mathrm{MeCN} \cdot 2 \mathrm{H}_{2} \mathrm{O}$} & bpb & trans & gradual & - & 61 \\
\hline 1D & VT & {$\left[\mathrm{Co}(3,5 \text {-dbdiox })_{2}(\mathrm{tpb})\right] \cdot \mathrm{H}_{2} \mathrm{O}$} & $\mathrm{tpb}$ & trans & gradual & - & 63 \\
\hline 1D & VT & {$\left[\mathrm{Co}(\text { tdde })_{2}\left(4,4^{\prime}-\mathrm{bpy}\right)\right] \cdot 2 \mathrm{H}_{2} \mathrm{O} \cdot 4,4^{\prime}-\mathrm{bpy}$} & 4,4'-bpy & trans & gradual. & - & 67 \\
\hline $2 \mathrm{D}$ & VT & {$\left[\left\{\mathrm{Co}(3,5 \text {-dbdiox })_{2}\right\}_{2}\right.$ (tpom) $) \cdot 2 \mathrm{EtOH} \cdot 8 \mathrm{H}_{2} \mathrm{O}$} & tpom & cis & $\begin{array}{l}\text { abrupt, } T_{1 / 2}=325 \mathrm{~K} \text {, } \\
\text { then gradual upon desolvation }\end{array}$ & $60 \mathrm{~K}$ & 68 \\
\hline
\end{tabular}

1 The compounds $\left[\mathrm{Co}(3, n\right.$-dbsq)(3,n-dbdiox)(NLN)] ( $n=5$ or 6$)$ are formulated here as $\left[\mathrm{Co}(3, n \text {-dbdiox })_{2}(\mathrm{NLN})\right]$ for brevity. 


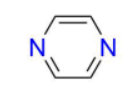

pyz

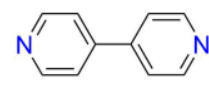

4,4'-bpy

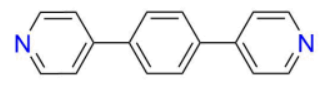

bpb

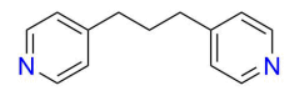

bpp

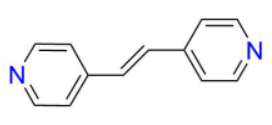

bpee

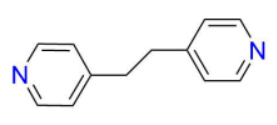

bpe

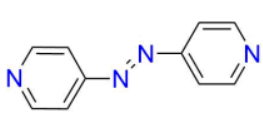

azpy

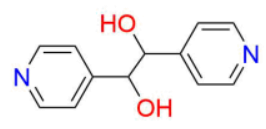

dpg

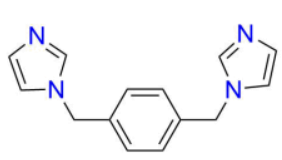

bix

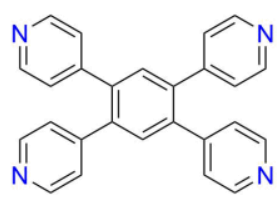

tpb

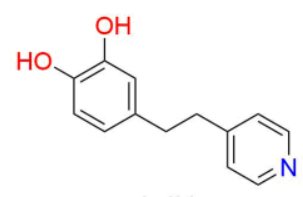

$\mathrm{pbdH}_{2}$

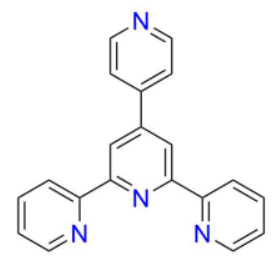

pyterpy

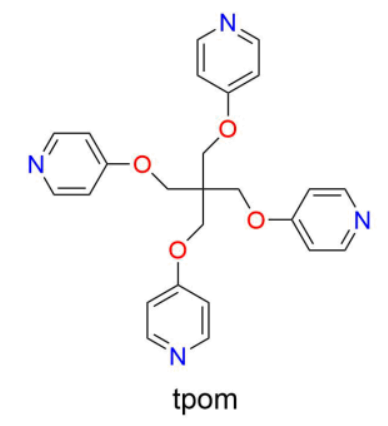

Fig. 2. Linking ligands for cobalt SCO and cobalt-dioxolene VT coordination polymers

\subsection{Spin crossover in one dimensional cobalt coordination polymers}

The first report of a SCO transition displayed by a cobalt CP was in 2004 by Hayami et al. [54]. The combination of $\mathrm{CoCl}_{2}$ and 4'-(4"'-pyridyl)-2,2':6',2"-terpyridine (pyterpy; Fig 2) afforded the $1 \mathrm{D}$ chain $\left[\mathrm{Co}\right.$ (pyterpy) $\left.\mathrm{Cl}_{2}\right] \cdot \mathrm{MeOH}$ (Fig. 3). Upon isolation, the compound readily exchanges methanol solvate molecules for water and the two different solvates exhibit distinctly different $\mathrm{SCO}$ behavior. While $\left[\mathrm{Co}(\right.$ pyterpy $\left.) \mathrm{Cl}_{2}\right] \cdot \mathrm{MeOH}$ remains in the temperatureinvariant $\mathrm{HS}-\mathrm{Co}(\mathrm{II})$ state up to room temperature, $\left[\mathrm{Co}\right.$ (pyterpy) $\left.\mathrm{Cl}_{2}\right] \cdot 2 \mathrm{H}_{2} \mathrm{O}$ exhibits an abrupt thermally-induced SCO transition between the LS and HS-Co(II) forms with $T_{1 / 2}=223 \mathrm{~K}$. Repeated heating-cooling cycles revealed a small reversible hysteresis loop $(\Delta T=1 \mathrm{~K})$. Subsequent studies of the bromo analogs, $\left[\mathrm{Co}\left(\right.\right.$ pyterpy) $\left.\mathrm{Br}_{2}\right] \cdot \mathrm{MeOH}$ and 
$\left[\mathrm{Co}\right.$ (pyterpy) $\left.\mathrm{Br}_{2}\right] \cdot 2 \mathrm{H}_{2} \mathrm{O}$, indicated slightly different structures and different SCO properties, with the hydrated and desolvated forms both exhibiting a gradual SCO transition [55]. While the connectivity is the same in the two complexes, the $\mathrm{Cl}-\mathrm{Co}-\mathrm{Cl}$ bonds are aligned parallel in each chain of the chloro-complex, but the $\mathrm{Br}-\mathrm{Co}-\mathrm{Br}$ vectors are offset in an alternating pattern, which affords different crystal packing for the compounds. All compounds exhibit intermolecular $\pi-\pi$ stacking interactions between the chains to generate a pseudo-3D network. These compounds illustrate the sensitivity of SCO transitions in CPs to solvation effects.

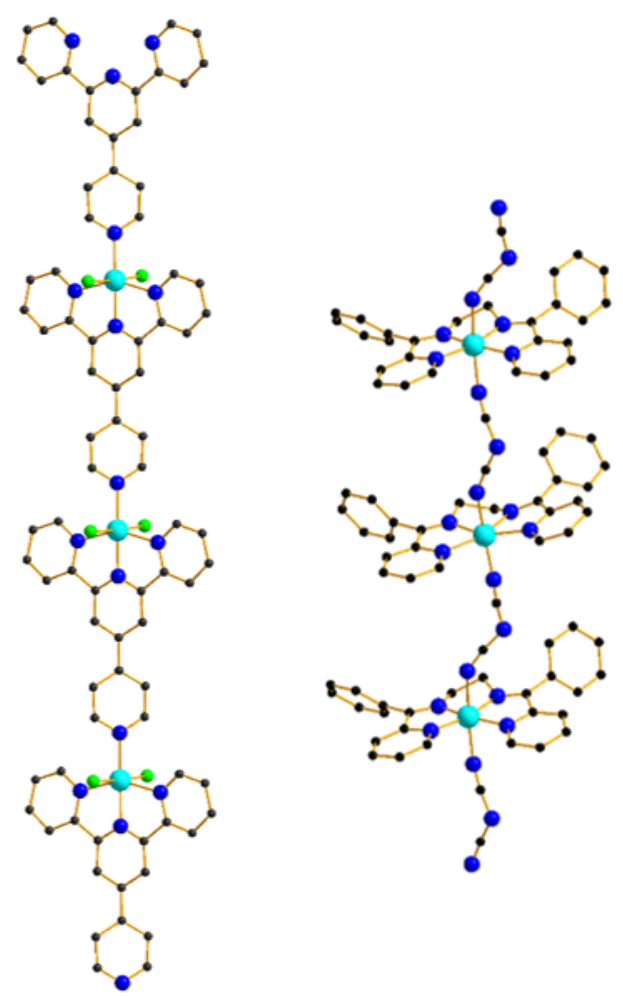

Fig. 3 Structures of $1 \mathrm{D}$ cobalt(II) SCO coordination polymers [Co(pyterpy)Cl $\left.\mathrm{Cl}_{2}\right]$ (left) and [Co(enbzpy)(dca) $]^{+}$(right) [54, 56]. Color code: Co (cyan), N (blue), C (black), $\mathrm{Cl}$ (green); H atoms omitted for clarity. 
In 2012, Costa and Ghosh et al. reported SCO for the 1D CP [Co-(enbzpy)(dca)](ClO 4$)$ (enbzpy = N,N'-bis(2-pyridinylbenzylidene)ethane-1,2-diamine, dca $^{-}=$dicyanamide; Fig 2) [56]. In this compound, trans-disposed dicyanamide ligands link $\{\mathrm{Co}(\mathrm{enzbpy})\}$ units into $1 \mathrm{D}$ chains (Fig. 3). The magnetic susceptibility measured in multiple cooling-heating cycles over the temperature range 2-300 K exhibits an abrupt SCO transition around $190 \mathrm{~K}$, with a reversible hysteresis loop of width $3 \mathrm{~K}$ (Fig 4). The transition is incomplete at low temperature and low temperature crystallography reveals that this is due to symmetry breaking associated with significant structural rearrangements and perturbation of intermolecular interactions. In particular, the perchlorate counterion undergoes reorientation that affects the anion- $\pi$ interactions with the dicyanamide bridge, which seem to play a significant role in the cooperative character of the SCO transition. The phenomenon was later confirmed by studies of a hexafluorophosphate salt of the same complex, which undergoes a gradual and nonhysteretic SCO transition [57]. The non-coordinating bulky hexafluorophosphate counterion does not take part in the intermolecular interactions around the cobalt center, the result being a much less well-defined SCO conversion. 

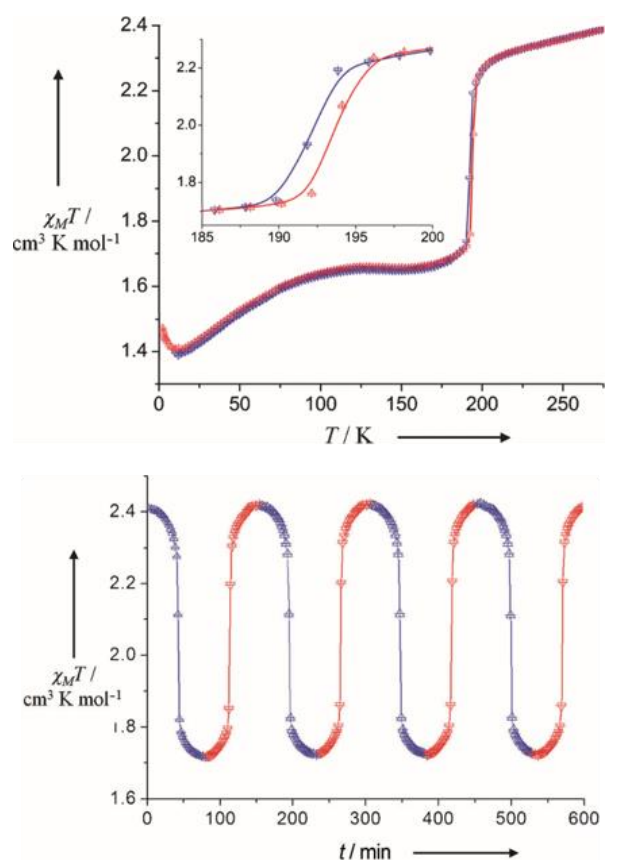

Fig. 4. (top) Plot of $\chi_{M} T$ versus $T$ for the $1 \mathrm{D} \mathrm{SCO} \mathrm{CP}\left[\mathrm{Co}(\right.$ enbzpy)(dca) $]\left(\mathrm{ClO}_{4}\right)$ illustrating the abrupt SCO transition with a small hysteresis loop of $3 \mathrm{~K}$ (inset); blue represents the magnetic data collected in cooling mode and red in warming mode. (bottom) Four thermal cycles in the temperature range $227-160 \mathrm{~K}$; the HS-LS transition is represented in blue and the LS-HS in red. Reproduced with permission from ref. 56. Copyright 2012 John Wiley and Sons.

\subsection{Valence tautomerism in one dimensional cobalt coordination polymers}

The first cobalt CP to display a VT transition was reported by Jung and Pierpoint in 1994 [58], a decade before the first $\mathrm{SCO}$ equivalent. The anaerobic reaction between $\mathrm{Co}_{2}(\mathrm{CO})_{8}, 3,6$-ditert-butyl-1,2-benzoquinone and pyrazine in hexane affords the neutral 1D CP [Co(3,6dbsq)(3,6-dbdiox)(pyz)] (3,6-dbsq = 3,6-di-tert-butylsemiquinone; 3,6-dbdiox = 3,6-di-tertbutyldioxolene). Temperature-dependent electronic spectroscopy and magnetic measurements indicate that the 1D chain undergoes a temperature-induced VT transition from the HSCo(II)-sq tautomer at $350 \mathrm{~K}$ to the $\mathrm{LS}-\mathrm{Co}(\mathrm{III})$-cat tautomer at $5 \mathrm{~K}$. 
For over a decade, no further VT CPs were reported until Ruiz-Molina et al. used the ditopic N-donor ligand 4,4'-bipyridine (4,4'-bpy; Fig 2) to link cobalt-dioxolene building blocks [59]. The 1D chain [Co(3,5-dbsq)(3,5-dbdiox)(4,4'-bpy)] was characterized by X-ray crystallography and magnetic measurements indicated an abrupt VT transition commencing above $250 \mathrm{~K}$ (Table 1). Subsequently J. Tao and C. Boskovic, together with their co-workers, have separately reported another eight 1D CPs (Table 1) of general formula $[\mathrm{Co}(3,5-\mathrm{dbsq})(3,5-$ dbdiox $)(\mathrm{NLN})] \cdot$ solv $(\mathrm{NLN}=$ meso- $\alpha, \beta$-di(4-pyridyl)glycol $(\mathrm{dpg})$, bis(4-pyridyl)ethylene (bpee), 4,4'-trans-azopyridine (azpy), 1,4-bis(4-pyridyl)-benzene (bpb), 1,2-bis(4pyridyl)ethane (bpe), 1,3-bis(4-pyridyl)propane (bpp), 1,2,4,5-tetra(4-pyridyl)benzene (tpb); Fig. 2) that undergo VT transitions [60-63]. Almost all these compounds possess a transdisposition of the linking ligands. A cis-disposition is evident for the dpg compound, affording a zig-zag chain (Fig. 5), while the bpp compound is comprised of an equal quantity of cischains and trans chains that are interwoven in layers (Fig 6). All these 1D chains exhibit thermally-induced VT transitions at temperatures above $100 \mathrm{~K}$, the characteristics of which tend to display a significant dependence on solvation/desolvation (Fig. 6.). Examination of the first derivative of the thermal dependence of the magnetic susceptibility for the bpp compound indicates two separate transitions, consistent with the presence of both cis and trans isomeric forms [62]. Measurements under pressure indicate that the VT transition for the dpg-linked chain is retarded upon increasing pressure, occurring at higher temperatures and exhibiting a more gradual profile [60]. This is consistent with the more compact LS-Co(III)-cat form being favored at higher pressure. The VT transitions for many of these compounds can also be induced by light irradiation, with effective $T_{\text {LIESST }}$ temperatures in the range $55-83 \mathrm{~K}$ (Table 1 ). 

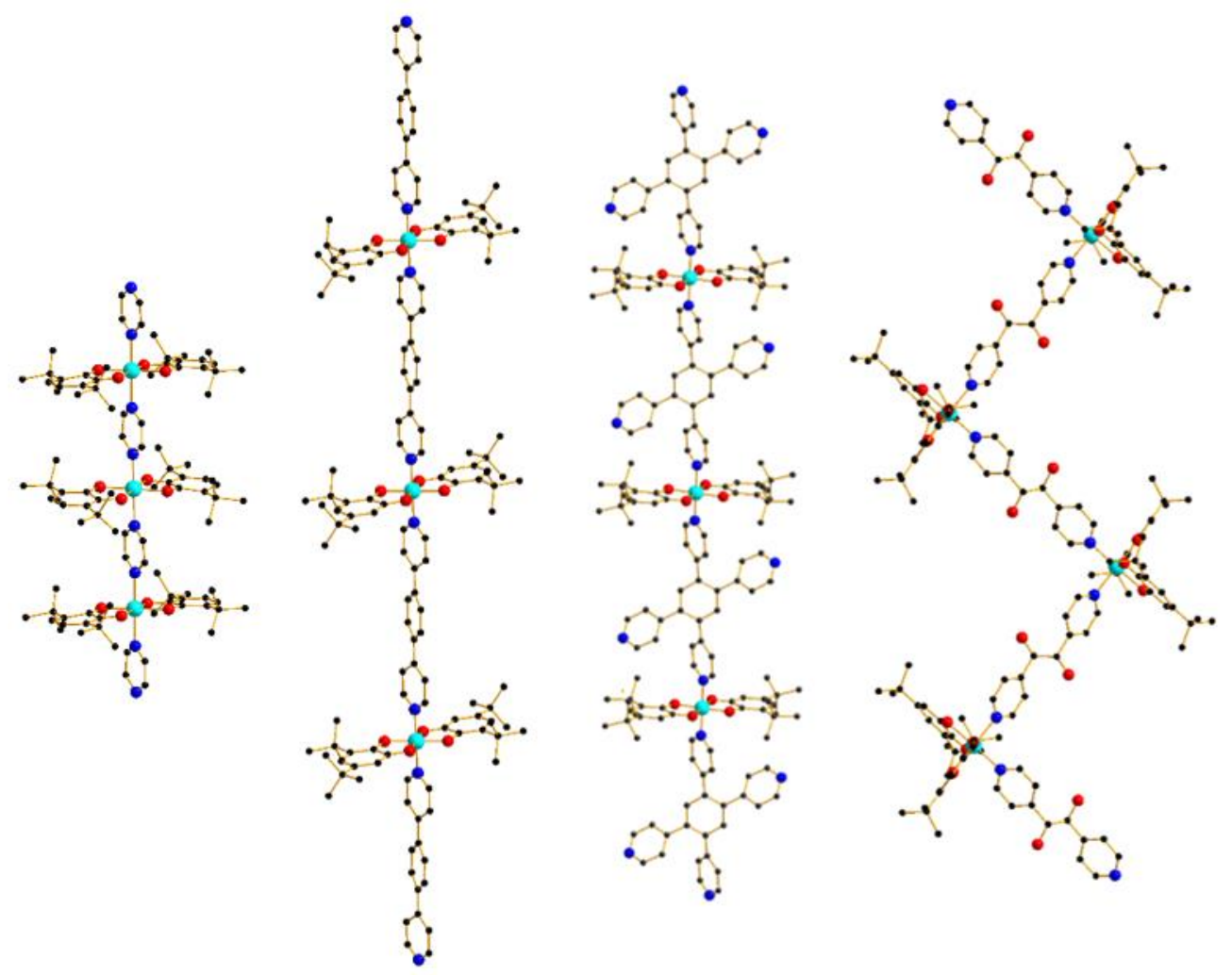

Fig. 5. Structures of $1 \mathrm{D}$ cobalt-dioxolene VT coordination polymers (from left to right): $[\mathrm{Co}(3,6-\mathrm{dbsq})(3,6-\mathrm{dbdiox})(\mathrm{pyz})]$ and $\left[\mathrm{Co}(3,5-\mathrm{dbsq})(3,5-\mathrm{dbdiox})_{2}(\mathrm{NLN})\right], \mathrm{NLN}=\mathrm{bpb}$, tpb and dpg (Fig 2) [58,60,61,63]. Color code as per Fig. 3 and O (red). 

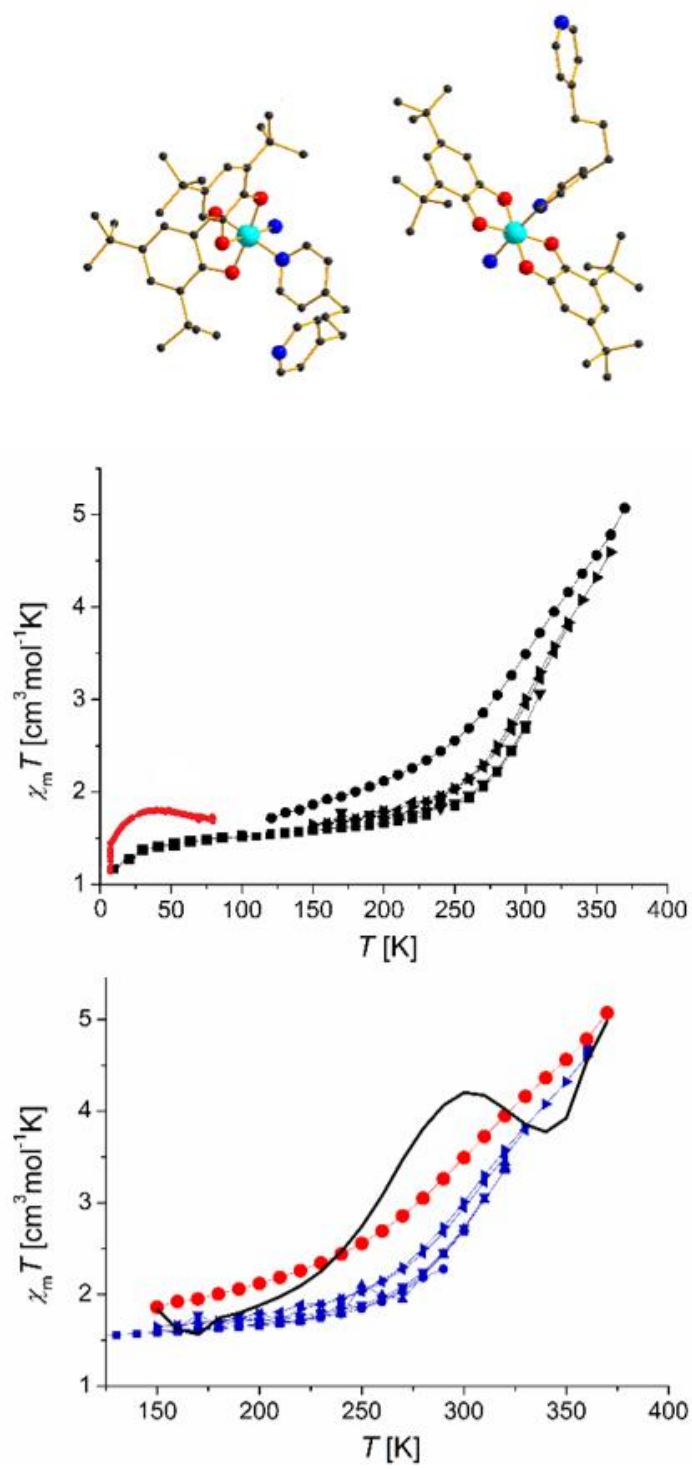

Fig. 6. (top) The cis and trans dispositions of the N-donor linkers at the cobalt centers for the two chains of the 1D cobalt-dioxolene CP [Co(3,5-dbsq)(3,5-dbdiox)(bpp)]; (middle) thermal (black) and light-induced (red) valence tautomeric transitions plotted as $\chi_{M} T$ versus $T$, with multiple heating and cooling cycles; (bottom) multiple heating and cooling cyles (blue) showing changes upon desolvation and the first derivative $\mathrm{d}\left(\chi_{M} T\right) / \mathrm{d} T$ (black line) of the final heating cyle (red) showing two distinct transitions [62].

Linking Co-bis(dioxolene) units with ditopic bipyridyl ancillary ligands has been the predominant approach to 1D VT CPs, however, it is also possible to link cobalt centers through 
the redox-active ligands. Efforts to generate VT CPs using the bis-bidentate dioxolene, or polyoxolene ligands 3,5-bis(3',4'-dihydroxy-5'-tert-butylphenyl)-1-tert-butylbenzene and 3,3,3',3'-tetramethyl-5,5',6,6'-tetrahydroxy-1,1'spiro-bis(indane), for instance with phenanthroline as an ancillary ligand, have afforded solid products that were not amenable to structural determination [64-66]. However, the compounds obtained exhibit thermallyinduced VT transitions in all cases, including with a $12 \mathrm{~K}$ hysteresis loop width in one case, indicative of strong cooperative interactions. Light-induced VT transitions were also reported for some of these compounds.

In principle, it might also be possible to link Co-dixolene VT units into a $\mathrm{CP}$ through two types of linking ligand, using both ancillary $\mathrm{N}$-donor linkers and bis-bidentate redox-active linking ligand, perhaps to generate 2D grid CPs. Sato et al. have employed this approach and combined bis-dioxolene 2,3-tetrahydroxy-9,10-dimethyl-9,10-dihydro-9,10-ethanoanthracene (tdde) and 4,4'-bpy ligands, although the compound obtained was the $1 \mathrm{D}$ chain $\left[\mathrm{Co}(\mathrm{tdde})_{2}(4,4\right.$ 'bpy)], with only the 4,4'-bpy serving as linkers [67]. The polymeric compound is a chiral helical chain that crystallizes in a chiral space group, despite the components being achiral. A gradual thermally-induced VT transition is evident above $100 \mathrm{~K}$.

\section{$5 \quad$ Two dimensional switchable cobalt coordination polymer}

The only example of a higher dimensional switchable cobalt CP was reported in 2011 by Tao, Zhang et al. (Table 1) [68]. The polypyridyl ligand (Fig. 2) tetrakis(4pyridyloxymethylene)methane (tpom) acts as a 4-connecting linker of cobalt-dioxolene units in $\left\{[\mathrm{Co}(3,5-\mathrm{dbsq})(3,5-\mathrm{dbdiox})]_{2}\right.$ (tpom) $\}$ (Fig. 7). The resulting 2D structure can be described as a layer of bridging tpom ligands 'sandwiched' between two layers of Co centers. The compound displays a VT transition, the characteristics of which are affected by the degree of solvation, indicated by measurements over two full cooling/heating cycles. During the first 
heating cycle, the compound undergoes an abrupt transition starting above $250 \mathrm{~K}$, but because of desolvation associated with heating the sample, the cycle cannot be repeated. In the second cycle, the magnetic susceptibility versus temperature curve of the desolvated sample does not show a well-defined interconversion temperature and therefore the VT conversion is assumed to be incomplete. However, once the sample is completely desolvated, the transition becomes reversible, although the sample loses crystallinity and the structural changes cannot be elucidated crystallographically. The VT interconversion can also be achieved by irradiation with blue light at low temperature.

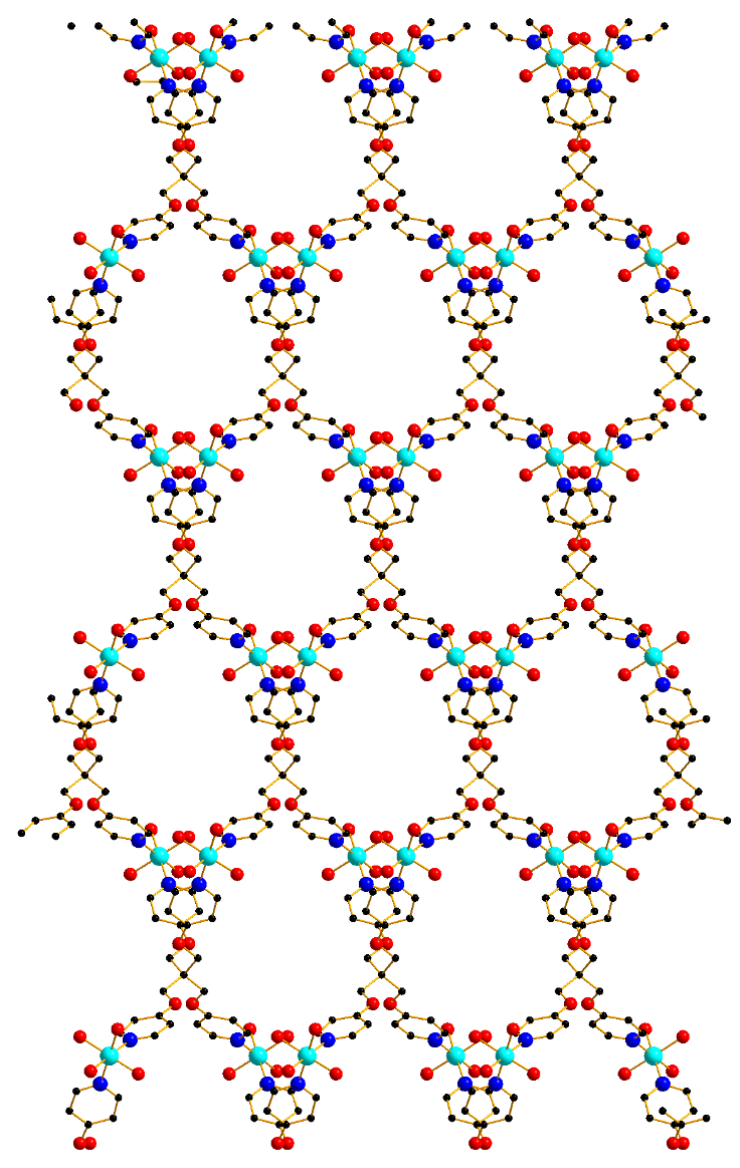

Fig. 7. The $2 \mathrm{D}$ VT coordination polymer $\left[\{\operatorname{Co}(3,5-\mathrm{dbsq})(3,5 \text {-dbdiox })\}_{2}\right.$ (tpom) $]$ [68]. Hydrogen atoms and dioxolene ligands omitted for clarity; color code as per Fig. 5. 


\section{New directions with switchable cobalt coordination polymers}

As described above, all but one of the cobalt SCO or VT CPs identified to date are 1D chains. It might be thought that as they lack the well-defined porosity of higher dimensional analogues, 1D CPs have less potential for materials applications. However, this is not at all the case and 1D CPs have proved to be eminently suitable to form gels, fibres, films, nanoparticles and microspheres, and for grafting onto surfaces [42]. Thus, switchable 1D CPs can allow integration of VT or SCO properties into functional materials and the SCO or VT transition can also be of use for characterizing the new material. The main challenge in designing appropriate materials is the very nature of the VT/SCO transition itself, as the characteristic features of the transitions, including transition temperature, abruptness and hysteresis, are highly dependent on factors beyond the molecule. Any change in supramolecular packing or solvation can profoundly affect the characteristics of the transition, or even switch it off. Nevertheless, considerable success has been achieved, in the main by Ruiz-Molina et al., who have focused primarily on the incorporation of 1D VT CPs into nanoparticles and microspheres $[59,69-74]$.

The first report of VT nanoparticles in 2008 described the synthesis of nanoparticles of the 1D CP [Co(3,5-dbsq)(3,5-dbdiox)(bix)] (bix = 1,4-bis(imidazol-1-ylmethyl)benzene; Fig 2), using a fast precipitation method [59]. The ditopic bix ligand links VT cobalt-dioxolene units. The resulting nanoparticles are spherical and amorphous and have diameters ranging from 75 to $200 \mathrm{~nm}$, as determined by scanning electron microscopy (SEM) and dynamic light scattering (DLS). The particle size can be controlled by the rate of addition of the precipitating solvent, which is water in this case. Magnetic susceptibility studies indicate a gradual VT transition above $250 \mathrm{~K}$. In subsequent work, the same group were able to incorporate fluorescent organic guest molecules into the amorphous [Co(3,5-dbsq)(3,5-dbdiox)(bix)] nanoparticles by both coordination to the $\mathrm{CP}$ backbone (replacing some of the 3,5-dbdiox 
ligands) and mechanical attachment [70]. A study of the kinetics of guest release provides insights into the potential of CP nanoparticles for drug release. In this case, the VT transition facilitates characterization of the amorphous nanoparticles. Replacement of the 3,5-dbdiox ligands altogether, with bis-bidentate dioxolene ligands, and reaction with the bix linker via an interfacial polymerization method, affords microspheres of a VT CP with diameters between 0.2 and $1.6 \mu \mathrm{m}$ [71]. Smaller nanoparticles (40 $\mathrm{nm}$ diameter) are instead obtained by the fast precipitation method. These particles are amorphous but still exhibit the characteristic VT transition. One of the bis-bidentate dioxolene ligands incorporates an imine group, which gives rise to $\mathrm{pH}$-dependent decomposition of the particles at $\mathrm{pH}$ around 5, while the particles are stable at $\mathrm{pH}$ 7. These results highlight possible approaches to $\mathrm{pH}$-responsive drug delivery by CP nanoparticles.

More work from Ruiz-Molina et al. involved a very detailed synthetic study exploring the dependence of the VT transition on variations in the synthetic method for microparticles based on the $\mathrm{CP}[\mathrm{Co}(3,5-\mathrm{dbsq})(3,5-\mathrm{dbdiox})(4,4$ '-bpy)] [69]. While still using the fast precipitation method, variation of the reagent concentration, temperature, solvent and the use or absence of surfactants, affords two distinct crystalline phases of microparticles of the CP: a sponge-like $\alpha$-phase and a rod-like $\beta$-phase (Fig. 8). Magnetic studies revealed that while both phases exhibit a gradual VT transition above $250 \mathrm{~K}$, the transition for the $\alpha$-phase occurs at temperatures around $50 \mathrm{~K}$ less than for the $\beta$-phase. This represents an important breakthrough in the ability to control the morphology and the resulting transition temperature of microcrystals of a switchable CP. 

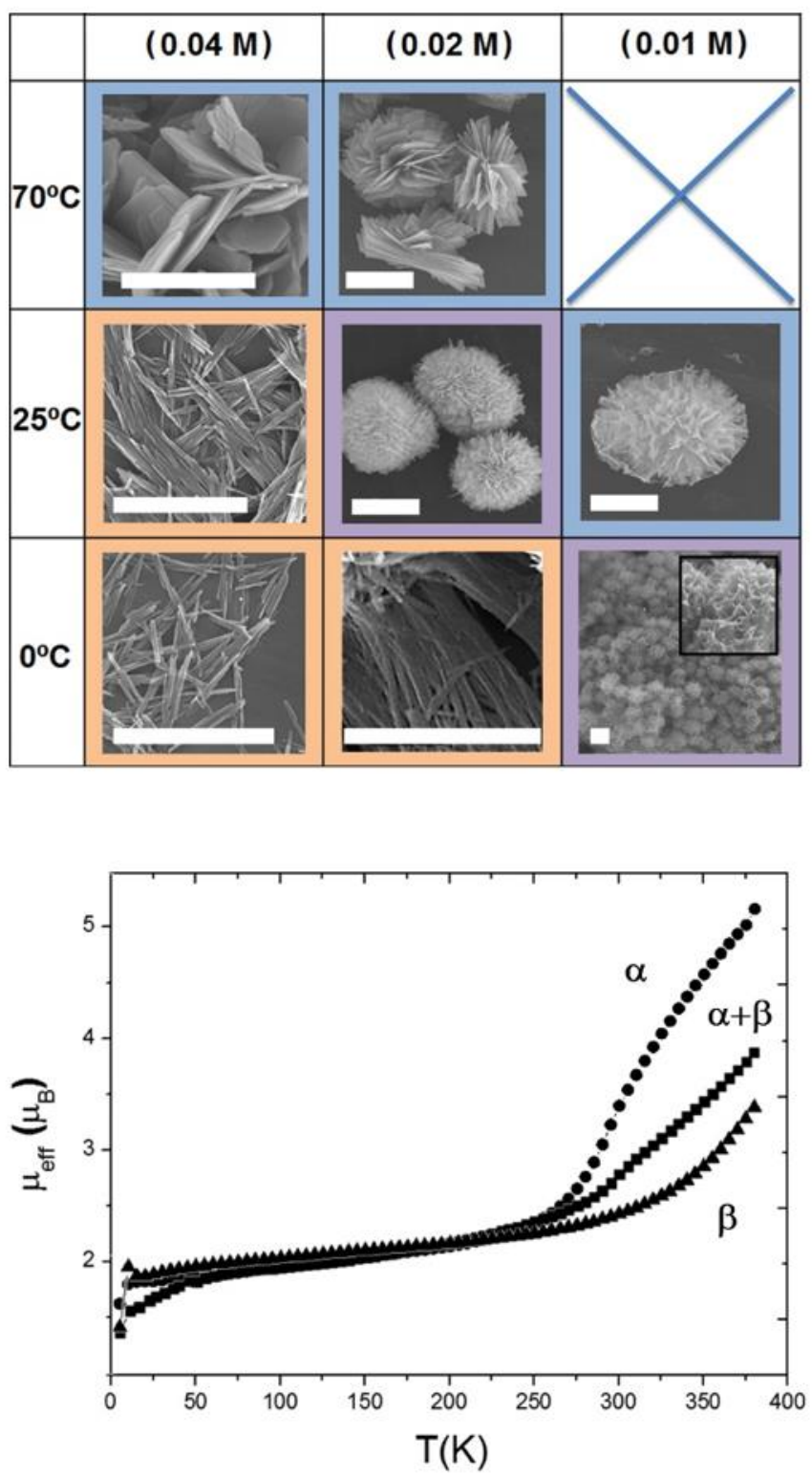

Fig. 8. (top) SEM images of VT CP microcrystals of [Co(3,5-dbsq)(3,5-dbdiox $)(4,4$ '-bpy)] obtained at different reagent concentrations and temperatures, as indicated in the figure. The different crystalline phases obtained are indicated with an arbitrary color code: $\alpha$-phase (blue), $\alpha+\beta$-phase (violet), $\beta$-phase (orange). Scale bar: $5 \mu \mathrm{m}$. (bottom) Plot of magnetic moment versus temperature of the two phases. Reproduced with permission from ref. 69. Copyright 2014, The American Chemical Society. 
An obvious extension of all the work based on $[\mathrm{Co}(3,5-\mathrm{dbsq})(3,5$-dbdiox $)(\mathrm{NLN})]$ VT CPs is to combine the dioxolene and pyridyl functionalities into a single ligand. The use of such a ligand, 4-(2-(pyridin-4-yl)ethyl)benzene-1,2-diol (pbdH 2 ; Fig. 2), with cobalt acetate, affords amorphous spherical nanoparticles of $110 \mathrm{~nm}$ diameter from the fast precipitation method [73]. Elemental analysis and energy dispersive X-ray spectroscopy are consistent with a 2:1 ratio of ligand to cobalt. The magnetic data indicate a very gradual VT transition in the temperature range $35-370 \mathrm{~K}$, which is accompanied by hysteresis. The temperature difference between the curves obtained upon heating and cooling has a maximum value of $12 \mathrm{~K}$. These compounds are the first nanoparticles to exhibit hysteresis associated with a VT transition.

Very recently, following successful attempts with discrete VT coordination complexes $[75,76]$ and iron SCO nanoparticles [43], attention has been brought to the synthesis of selfassembled monolayers of VT CP particles [72]. The nanoparticles employed for this purpose are amorphous $130 \mathrm{~nm}$ diameter particles of [Co(3,4-dhcSQ)(3,4-dhcCat)(bix)] (3,4-dhcSQ and 3,4dhcCat are the semiquinonate and catecholate forms of 3,4-dihydroxycinnamic acid, respectively). The pendant carboxylic acid groups can attach to a gold surface previously decorated with a monolayer of amino-terminated alkyl chains through a carbodiimide-mediated amide coupling reaction (Fig. 9). Ultimately, a uniform (85\% - 90\% coverage) 2D monolayer of the VT CPs is obtained. Although the VT transition in the nanoparticles was verified by magnetometry, this was not possible for the surface-immobilized nanoparticles due to the very small quantity and relatively low sensitivity of the technique. Instead, variable temperature XPS indicates a decrease in the proportion of LS-Co(III) and an increase in the amount of HS$\mathrm{Co}(\mathrm{II})$ as the temperature is increased from 80 to $393 \mathrm{~K}$, consistent with the existence of a VT transition. 
a

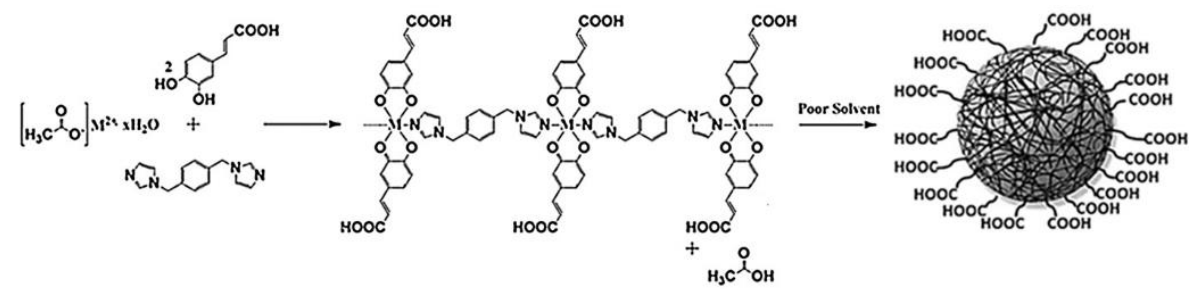

b

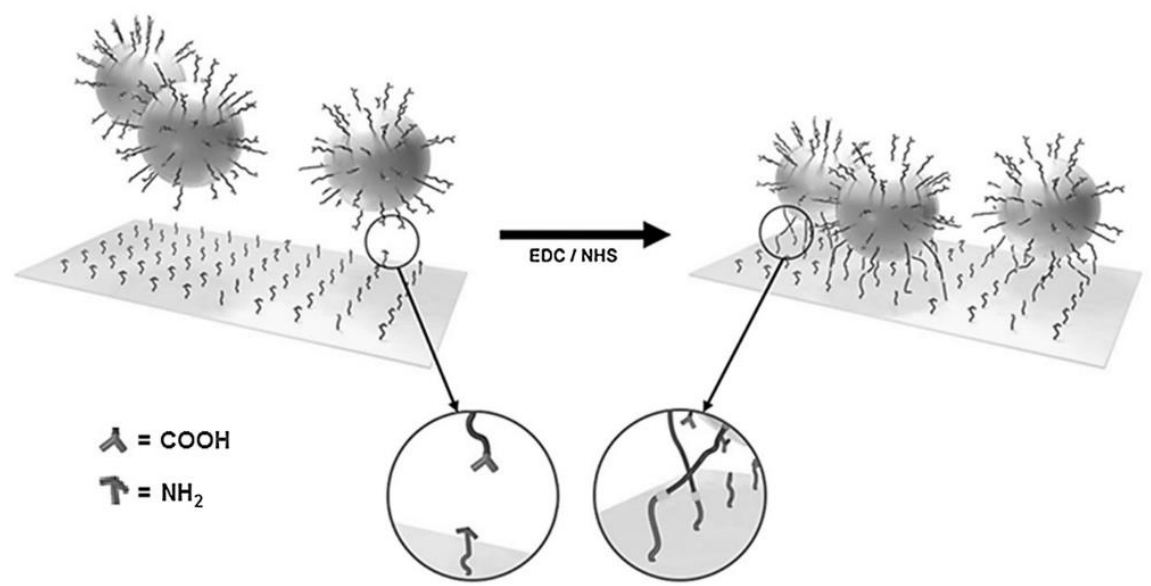

Fig. 9. (a) Scheme of the formation of the 1D VT CP $[\mathrm{Co}(3,4-\mathrm{dhcSQ})(3,4-\mathrm{dhcCat})(\mathrm{bix})]$ and assembly into nanoparticles. (b) Scheme of the attachment of carboxyl-functionalized nanoparticles onto a gold surface previously covered with monolayer of amino-terminated alkyl chains through a carbodiimine-mediated coupling reaction. Reproduced with permission from ref. 72. Copyright 2015, John Wiley and Sons.

\section{$7 \quad$ Concluding remarks}

The substantial research effort dedicated to imparting functionality into coordination polymers and optimizing the resultant properties is a testament to the promise of these materials for applications in advanced materials and devices. Concerning switchable, or electronically labile CPs, those based on SCO in iron(II) have been the most extensively investigated, while efforts with other metals have lagged behind. For switchable cobalt-based systems, many 1D CPs and a single 2D CP have been reported, with VT transitions significantly outstripping SCO. This is in part due to the larger cobalt-ligand bond length changes associated with the VT transition 
in cobalt-dioxolene compounds versus the smaller change that accompanies SCO in cobalt(II), which is also associated with an ability to induce the VT transition by light in a manner that is not possible for cobalt(II) SCO. For most of the structurally characterized examples, ditopic nitrogen-donor ligands link SCO or VT moieties into 1D chains. In the case of VT complexes, the possibility of linking the VT moieties through the redox-active ligands has been little pursued and could offer an alternative approach to tuning the characteristics of the VT transition, for instance by increasing the hysteresis loop width.

An exciting route to switchable materials suitable for practical applications is the synthesis of nano- or microparticles of VT CPs. In some cases, enhanced hysteresis is observed for these particles. The particles can then be grafted onto surfaces as robust self-assembled monolayers, with maintenance of the VT properties, which represents an important step towards permanent hybrid materials for incorporation into devices. In principle, the switchability associated with the VT transition can be intrinsically important for the specific functionality of the particles, or it can instead offer a means of monitoring the composition of the particles, for instance for applications in drug delivery.

A key aspect of both SCO and VT transitions is that the two interconverting forms can be readily distinguished, because of their different electronic, magnetic and structural properties and sometimes simply because they are different colors. Iron(II) SCO coordination polymers provide inspiration for the possibilities with switchable CPs, but cobalt-based systems remain relatively underexplored. While VT rather than SCO is probably more promising for cobalt systems, future promising options include combining cobalt-dioxolene moieties into CPs with other metals or metalloligands. Valence tautomerism is not limited to cobalt-dioxolene systems and variation of the redox-active ligand may provide interesting and/or useful materials. Suitably porous systems will likely be amenable to tuning the VT transition through host-guest interactions, and more dedicated efforts at inducing porosity into 
VT CPs may prove profitable. Ultimately, the intramolecular electron transfer that is key to VT transitions, but absent in simple SCO transitions, has the potential afford applications that are otherwise inaccessible, for instance involving electrical conduction, donor/acceptor interactions or properties based on magnetic exchange or ordering.

\section{References}

[1] H.J. Buser, A. Ludi, D. Schwarzenbach, W. Petter, Inorg. Chem. 16 (1977) 2704.

[2] R. Robson, Dalton Trans. (2008) 5113

[3] O.M. Yaghi, M. O’Keeffe, N.W. Ockwig, H.K. Chae, M. Eddaoudi, J. Kim, Nature. 423 (2003) 705.

[4] S.R. Batten, S.M. Neville, D.R. Turner, Coordination Polymers: Design, Analysis and Application, Royal Society of Chemistry, 2009.

[5] L. R. MacGillivray, ed., Metal-Organic Frameworks: Design and Application, John Wiley \& Sons, Hoboken, NJ, USA, 2010.

[6] D. Farrusseng, ed., Metal-Organic Frameworks: Applications from Catalysis to Gas Storage, Wiley-VCH Verlag GmbH \& Co. KGaA, Weinheim, 2011.

[7] S. Kitagawa, R. Kitaura, S. Noro, Angew. Chem. Int. Ed. Engl. 43 (2004) 2334.

[8] A.U. Czaja, N. Trukhan, U. Müller, I Chem. Soc. Rev. 38 (2009) 1284.

[9] K. Sumida, D.L. Rogow, J. A. Mason, T.M. McDonald, E.D. Bloch, Z.R. Herm, T.-H. Bae, J.R. Long, Chem. Rev. 112 (2012) 724.

[10] G. Maurin, C. Serre, A. Cooper, G. Férey, Chem. Soc. Rev. 46 (2017) 3104.

[11] M.B. Robin, Inorg. Chem. 1 (1962) 337.

[12] H. Miyasaka, Acc. Chem. Res. 46 (2013) 248.

[13] L. Sun, M.G. Campbell, M. Dinca, Angew. Chem. Int. Ed. 55 (2016) 3566.

[14] R. Medishetty, J.K. Zare, D. Mayer, M. Samoc, R.A. Fischer, Chem. Soc. Rev. 46 (2017) 
4976.

[15] A. Hauser, Top. Curr. Chem. 234 (2004) 155.

[16] J.-F. Létard, J. Mater. Chem. 16 (2006) 2550.

[17] D. Unruh, P. Homenya, M. Kumar, R. Sindelar, Y. Garcia, F. Renz, Dalton Trans. 45 (2016) 140008.

[18] Garcia Y., V. Niel, M.C. Muñoz, J.A. Real, Top. Curr. Chem. 233 (2004) 229.

[19] M.C. Muñoz, J.A. Real, T. Coord. Chem. Rev. 255 (2011) 2068.

[20] M.C. Muñoz, J.A. Real, in: "Spin-Crossover Materials - Properties and Applications", M.A. Halcrow (Ed.), 2013, John Wiley \& Sons, Chichester, UK, 121-138.

[21] O. Kahn, J. Kröber, C. Jay, Adv. Mater. 4 (1992) 718.

[22] K. Otsubo, T. Haraguchi, H. Kitagawa, Coord. Chem. Rev. 346 (2017) 123.

[23] Z.P. Ni, J.L. Liu, M.N. Hoque, W. Liu, J.Y. Li, Y.C. Chen, M.L. Tong, Coord. Chem. Rev. 335 (2017) 28.

[24] N.F. Sciortino, K.R. Scherl-Gruenwald, G. Chastanet, G.J. Halder, K.W. Chapman, J.F. Létard, C.J. Kepert, Angew. Chem. Int. Ed. Engl. 51 (2012) 10154.

[25] M. Ohba, K. Yoneda, G. Agusti, M.C. Muñoz, A.B. Gaspar, J. A. Real, M. Yamasaki, H. Ando, Y. Nakao, S. Sakaki, S. Kitagawa, Angew. Chem. Int. Ed. 48 (2009) 4767.

[26] P.D. Southon, L. Liu, E. A. Fellows, D.J. Price, G.J. Halder, K.W. Chapman, B. Moubaraki, K.S. Murray, J.F. Létard, C.J. Kepert, J. Am. Chem. Soc. 131 (2009) 10998.

[27] X. Bao, H.J. Shepherd, L. Salmon, G. Molnár, M.L. Tong, A. Bousseksou, Angew. Chem. Int. Ed. 52 (2013) 1198.

[28] J.E. Clements, J.R. Price, S.M. Neville, C.J. Kepert, Angew. Chem. Int. Ed. 55 (2016) 15105.

[29] N.F. Sciortino, K.A. Zenere, M.E. Corrigan, G.J. Halder, G. Chastanet, J.-F. Létard, C.J. Kepert, S.M. Neville, Chem. Sci. 8 (2017) 701. 
[30] H.A. Goodwin, Top. Curr. Chem. 234 (2004) 23.

[31] I. Krivokapic, M. Zerara, M. Daku, A. Vargas, C. Enachescu, C. Ambrus, P. TregennaPiggott, N. Amstutz, E. Krausz, A Hauser, Coord. Chem. Rev. 251 (2007) 364.

[32] D.N. Hendrickson, C.G. Pierpont, Top. Curr. Chem. 1 (2004) 63.

[33] T. Tezgerevska, K.G. Alley, C. Boskovic, Coord. Chem. Rev. 268 (2014) 23.

[34] A. Dei, D. Gatteschi, C. Sangregorio, L. Sorace, Acc. Chem. Res. 37 (2004) 827.

[35] E. Evangelio, D. Ruiz-Molina, Eur. J. Inorg. Chem. 2005 (2005) 2957.

[36] O. Sato, A. Cui, R. Matsuda, J. Tao, S. Hayami, Acc. Chem. Res. 40 (2007) 361.

[37] E. Evangelio, D. Ruizmolina, Compt. Rend. Chim. 11 (2008) 1137.

[38] A. Dei, L. Sorace, Appl. Magn. Reson. 38 (2010) 139.

[39] H.-C. Chang, D. Kiriya, Eur. J. Inorg. Chem. 2013 (2013) 642.

[40] C. Boskovic, in: "Spin-Crossover Materials - Properties and Applications", M.A. Halcrow (Ed.), 2013, John Wiley \& Sons, Chichester, UK, 203-224.

[41] A. Tissot, New J. Chem. 38 (2014) 1840.

[42] W.L. Leong, J.J. Vittal, Chem. Rev. 111 (2011) 688.

[43] A. Bousseksou, G. Molnár, L. Salmon, W. Nicolazzi, Chem. Soc. Rev. 40 (2011) 3313.

[44] M.G. Cowan, J. Olguín, S. Narayanaswamy, J.L. Tallon, S. Brooker, J. Am. Chem. Soc. 134 (2012) 2892.

[45] C. Roux, J. Zarembowitch, J.P. Itie, M. Verdaguer, E. Dartyge, A. Fontaine, H. Tolentino, Inorg. Chem. 30 (1991) 3174.

[46] O. Sato, Acc. Chem. Res. 36 (2003) 692.

[47] M. Graf, G. Wolmershäuser, H. Kelm, S. Demeschko, F. Meyer, H.-J. Krüger, Angew. Chem. Int. Ed. Engl. 49 (2010) 950.

[48] F. Rupp, K. Chevalier, M. Graf, M. Schmitz, H. Kelm, A. Grün, M. Zimmer, M. Gerhards, C. van Wüllen, H.-J. Krüger, R. Diller, S Chem. Eur. J. 23 (2017) 2119.. 
[49] C. Roux, D.M. Adams, J.P. Itie, A. Polian, D.N. Hendrickson, M. Verdaguer, Inorg. Chem. 35 (1996) 2846.

[50] I. Markevtsev, M. Monakhov, V. Platonov, A. Mischenko, A. Zvezdin, M. Bubnov, G. Abakumov, V. Cherkasov, J. Magn. Magn. Mater. 300 (2006) e407.

[51] G. Poneti, M. Mannini, L. Sorace, P. Sainctavit, M.-A. Arrio, E. Otero, J.C. Cezar, A. Dei, Angew. Chem. Int. Ed. Engl. 49 (2010) 1954.

[52] A. Droghetti, S. Sanvito, Phys. Rev. Lett. 107 (2011) 47201.

[53] T.M. Francisco, W.J. Gee, H.J. Shepherd, M.R. Warren, D.A. Shultz, P.R. Raithby, C.B. Pinheiro, J. Phys. Chem. Lett. 8 (2017) 4744.

[54] S. Hayami, K. Hashiguchi, G. Juhász, M. Ohba, H. Okawa, Y. Maeda, K. Kato, K. Osaka, M. Takata, K. Inoue, Inorg. Chem. 43 (2004) 4124.

[55] R. Ohtani, K. Shimayama, A. Mishima, M. Ohba, R. Ishikawa, S. Kawata, M. Nakamura, L.F. Lindoy, S. Hayami, J. Mater. Chem. C. 3 (2015) 7865.

[56] K. Bhar, S. Khan, J.S. Costa, J. Ribas, O. Roubeau, P. Mitra, B.K. Ghosh, Angew. Chem. Int. Ed. 51 (2012) 2142.

[57] S. Roy, S. Choubey, K. Bhar, N. Sikdar, J.S. Costa, P. Mitra, B.K. Ghosh, Dalton Trans. $44(2015) 7774$.

[58] O. Jung, C.G. Pierpont, J. Am. Chem. Soc. 116 (1994) 2229.

[59] I. Imaz, D. Maspoch, C. Rodríguez-Blanco, J.M. Pérez-Falcón, J. Campo, D. RuizMolina, Angew. Chem. Int. Ed. Engl. 47 (2008) 1857.

[60] L. Chen, R. Wei, J. Tao, R. Huang, L. Zheng, Sci. China Chem. 55 (2012) 1037.

[61] X. Chen, R. Wei, L. Zheng, J. Tao, Inorg. Chem. 53 (2014) 13212.

[62] O. Drath, R.W. Gable, B. Moubaraki, K.S. Murray, G. Poneti, L. Sorace, C. Boskovic, Inorg. Chem. 55 (2016) 4141.

[63] O. Drath, R.W. Gable, G. Poneti, L. Sorace, C. Boskovic, Cryst. Growth Des. 17 (2017) 
3156.

[64] A. Beni, A. Dei, D. A. Shultz, L. Sorace, Chem. Phys. Lett. 428 (2006) 400.

[65] M. Affronte, A. Beni, A. Dei, L. Sorace, Dalton Trans. (2007) 5253.

[66] S.H. Bodnar, A. Caneschi, A. Dei, D.A. Shultz, L. Sorace, Chem. Commun. 2001 (2001) 2150.

[67] W.Q. Cheng, G.L. Li, R. Zhang, Z.H. Ni, W.F. Wang, O. Sato, J. Mol. Struct. 1087 (2015) 68.

[68] B. Li, L.-Q. Chen, R.-J. Wei, J. Tao, R.-B. Huang, L.-S. Zheng, Z. Zheng, Inorg. Chem. $50(2011) 424$.

[69] F. Novio, J. Campo, D. Ruiz-Molina, Inorg. Chem. 53 (2014) 8742.

[70] L. Amorin-Ferre, F. Busque, J.L. Bourdelande, D. Ruiz-Molina, J. Hernando, F. Novio, Chem. Eur. J. 19 (2013) 17508.

[71] F. Nador, F. Novio, D. Ruiz-Molina, Chem. Commun. 50 (2014) 14570.

[72] P. Gonz??lez-Monje, F. Novio, D. Ruiz-Molina, Chem. Eur. J. 21 (2015) 10094.

[73] M. Guardingo, F. Busqué, F. Novio, D. Ruiz-Molina, Inorg. Chem. 54 (2015) 6776.

[74] F. Novio, C. Roscini, C. Bellacanzone, M. Guardingo, J. Hernando, J. Mater. Chem. C. $4(2016) 5879$.

[75] S. Bin-Salamon, S. Brewer, S. Franzen, D.L. Feldheim, S. Lappi, D. A Shultz, J. Am. Chem. Soc. 127 (2005) 5328.

[76] G. Poneti, L. Poggini, M. Mannini, B. Cortigiani, L. Sorace, E. Otero, P. Sainctavit, A. Magnani, R. Sessoli, A. Dei, Chem. Sci. 6 (2015) 2268. 
Graphical Abstract

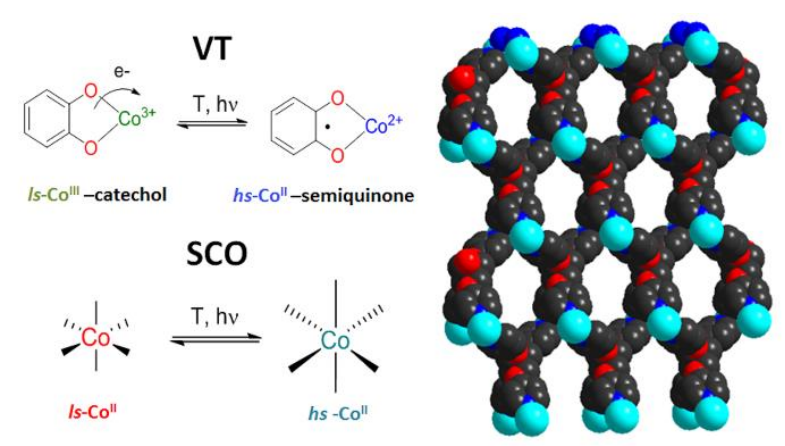

